\title{
Manipulating flow velocity to manage fish reproductions in dammed rivers
}

\author{
Qiuwen Chen ${ }^{1}$, Lei Tang ${ }^{1}$, Jun Wang ${ }^{1}$, Kangle $\mathrm{Mo}^{1}$, Yuchen Chen ${ }^{1}$, Yuqing Lin $^{1}$, and Yong \\ $\mathrm{GaO}^{2}$ \\ ${ }^{1}$ Nanjing Hydraulic Research Institute \\ ${ }^{2}$ China Three Gorges Corporation
}

May 5, 2020

\begin{abstract}
Managing reproduction is the most effective approach to sustain population or control invasion of species. Flow velocity is recognized to affect the reproduction of fishes spawning drifting eggs in rivers. Despite plenty of studies on this aspect, quantitative relations between flow velocity and fish reproduction, including spawning, fertilizing, hatching and surviving, has not yet been established. Here we for the first time quantified the relationship between flow velocity and reproduction of Chinese carps through lab experiments as well as field surveys. The results showed that a minimum velocity was required to trigger Hypophthalmichthys molitrix (H. molitrix) releasing eggs, and a velocity range was preferential to sustain spawning activity. However, the embryo incubation and larvae development of H. molitrix were found to be inhibited with the increase in flow velocity. Considering the requirements of spawning and hatching as well as larvae development, a compromised optimal flow velocity was identified for reproduction of $\mathrm{H}$. molitrix in rivers. The findings were of great significance to guide the operation of cascade dams to create suitable flow velocities during reproduction season for either improving population or impeding invasion of carps.
\end{abstract}

\section{Introduction}

Conservation of endangered species and control of invasive species are a great ecological challenge worldwide. River damming for flood control and hydropower generation not only alters the natural hydrologic regime, water quality and sediment flux (Poff \& Schmidt 2016; Best 2019), but also results in undesirable ecological effects, particularly in terms of fish community (Stone 2016; Cooper et al. 2017). Dam operations affect the reproductive activity of native fish species and thus alter their populations and communities (Normando et al. 2014; Zhanget al. 2019), which has been reported on rivers around the world, such as the Madeira River in Amazon (Cella-Ribeiro et al. 2017), the Colorado River in USA (Finch et al. 2015), and the Lancang River in China (Zhang et al. 2019). Fish spawning activity is likely triggered by a wide range of environmental factors, including discharge (Buddendorf et al. 2017), water temperature (King et al. 2016), dissolved oxygen (Fellman et al. 2019), turbidity (Glotzbecker et al. 2015), and primary production (McBride et al. 2015). Flow velocity is proved particularly critical to the reproduction of fishes spawning drifting eggs (Davieset al. 2014; Lechner et al. 2014; Fellman et al.2019).

Chinese carps, which include Silver carp (Hypophthalmichthys molitrix), grass carp (Ctenopharyngodon idellus ), black carp (Mylopharyngodon piceus ) and bighead carp (Aristichthys nobilis ), play important roles in both cultivation and capture fishery nationwide (Cao et al. 2015). In the 20th century, $60 \%$ of the entire catch of freshwater fishes in the Yangtze River was composed of Chinese carps (Duan et al. 2009). However, in the last decades, due to the remarkable changes in hydrological conditions caused by the construction of the Gezhouba Dam and the Three Gorges Dam, the spawning activities of the Chinese carp 
species have been severely impacted. In 2003, the number of fish eggs and larvae was $10 \%$ of that in 2002 , when the Three Gorges Reservoir started operation (Xie \& Chen 2001; Liet al. 2013).

In other places, Chinese carps have become one of the most disastrous invasive species (Fig. S1 in Supporting Information). Due to their biological attributes such as high fecundities and movement rates, the populations expanded rapidly, and successfully invaded into many rivers and lakes (Solomon et al. 2016). In the United States, the explosion of Chinese carp populations has caused serious decline of native fish populations (Chick et al. 2019). In Australia, Chinese carps sustain high biomasses (up to $3144 \mathrm{~kg} / \mathrm{ha}$ ) in many rivers (Koehn 2016). In China, many native or endemic species in plateau lakes have been destructively impacted by the introduction of bighead and silver carp (Ding et al. 2017), leading to irreversible ecological changes. Despite a variety of measures have been taken to control Chinese carps, even a highly risk idea is proposed to release virus to prevent the expansion of Chinese carp population in Australia (Kopf et al. 2017; Marshall et al. 2018), little effective outcome has been achieved so far.

Managing the reproduction could be an effective measure to sustain the population or control the invasion of Chinese carps. Chinese carps typically spawn in large and turbid rivers, and the lowest water temperature for spawning is $18{ }^{\circ} \mathrm{C}$ with peak spawning at $21-24{ }^{\circ} \mathrm{C}$, and particularly an increase in flow is a key factor to sustain spawning (Xuet al. 2015). Although it is agreed that flow velocity is crucial to the spawning activities of Chinese Carps (Davies et al. 2014; Lechner et al. 2014; Fellman et al. 2019), no direct evidence or quantitative relationship between spawning activities and flow velocity has been established.

Here we took $H$. molitrix as the target species and used a physical model to test two hypotheses: (1) there exists a quantitative relationship between flow velocity and the spawning activity as well as embryo development of Chinese carp; (2) there exists an optimal flow velocity balancing both the requirements of spawning activity and embryo development. Meanwhile, multiple-year field surveys of Chinese carp spawning were conducted to cross-evidence the control experiments. The results provide a theoretical clue to improve or impede carp reproduction by adaptive management of hydraulic structures.

\section{Material and methods}

All the experiments were conducted in Dangtu Experimental Centre of Nanjing Hydraulic Research Institute, China under a permission in accordance with the guidelines of the Institutional Animal Care and Use Committees (IACUC).

Collection of fish eggs in the field. Samples of drifting eggs were collected at a fixed cross-section, which is near Yidu City (Fig. S2 in Supporting Information), in the main stream of Yangtze River from 2012 to 2016. Larvae and drifting eggs of Chinese carps were frequently monitored at this cross-section during the reproduction period. The reach from Yichang to Yangjiazui, which is about $10 \mathrm{~km}$ upstream of the crosssection, is reported to be the spawning ground (Yi et al.2010). The reach is nearly $1 \mathrm{~km}$ wide, and has neither erodible riffles nor narrow sections. These special morphological features create suitable flow conditions that benefit to Chinese carp spawning.

During the five years survey, sampling started at mid-May in each year, when water temperature was higher than the threshold of $18^{\circ} \mathrm{C}$. The sampling continued for two consecutive weeks until no egg was found. Fish eggs were collected from 8:00 to 9:00 and from 14:00 to 15:00 every day during the sampling period. A net ( $0.5 \mathrm{~m}$ diameter, $500 \mu \mathrm{m}$ mesh) was used to collect drifting eggs. The net was suspended on the water surface and was oriented to upstream against the flow. A propeller-type current meter was used to measure the flow velocity simultaneously. The corresponding discharge $\left(\mathrm{m}^{3} / \mathrm{s}\right)$ at the upstream boundary and water level $(\mathrm{m})$ at the downstream boundary of the reach were obtained from Changjiang Water Resources Commission.

The collected eggs were immediately examined. The eggs with a diameter of $4 \sim 5 \mathrm{~mm}$ were considered as potential Chinese carp eggs. Developmental stages and post-fertilization time at collection were both identified. The identified eggs were incubated in the laboratory until their species were confirmed, so that egg density (eggs/1,000 $\mathrm{m}^{3}$ ) of each sampling was finally estimated.

To obtain the flow field of the entire reach, a two-dimensional unsteady hydrodynamic model was developed. 
The model was calibrated and validated by the obtained data of discharge and water level as well as the measured cross-section velocity. The details of the model description, calibration and verification of the hydrodynamics model were presented in Text S1 in Supporting Information. The calibrated model was then used to calculate the flow velocity of the entire river reach.

Based on the calculated flow velocity and the embryonic development time (drift time), the upstream spawning sites were located by computing the drift distance away from the egg collection cross-section (Text S2 in Supporting Information). The corresponding flow velocities of each spawning event at the located sites were then extracted from the modeled flow field (Fig. S2 in Supporting Information) and were used for further analysis.

Laboratory experiments. The experiment was conducted from May $15^{\text {th }}$ to June $20^{\text {th }}$ in 2017 and 2018, respectively. The experimental device was a large annular flume (Fig. S3a in Supporting Information). Two submerged water impellers and four submerged pumps were installed to accelerate the flow of water. The middle of the straight sections was widened and deepened to facilitate the placement of the submerged water impeller, and fishing nets were installed on both sides to prevent the silver carps from entering into the impeller area. Twenty-two measuring points were arranged around the flume, and the velocity at $0.5 \mathrm{~m}$ depth was measured by velocimeters. There were five underwater cameras around the flume to observe the spawning behavior of $H$. molitrix . During the experiment, the water depth was set at $0.9 \mathrm{~m}$ and the water quality was consistent with that of the acclimation pond. Water quality parameters were measured using a multifunctional water quality analyzer (YSI 650MDS, USA). The experiment designed six scenarios with different theoretically maximum velocities (Table S1 in Supporting Information).

Sexually mature males (length: $37 \pm 1.3 \mathrm{~cm}$, weight: $3.6 \pm 0.4 \mathrm{~kg}$, number: 72 ) and females (length: $43 \pm$ $2.1 \mathrm{~cm}$, weight: $4.5 \pm 0.6 \mathrm{~kg}$, number: 72$)$ of $H$. molitrix were obtained from the Chinese carps Hatchery Center in Huanggang City, Hubei Province, China. Before the experiments, they were placed in a net cage in an acclimation pond. A commercial fish diet was supplied to satiation twice a day. After seven days, six male and six female H. molitrix were randomly selected as a group for experiment. Before being moved into the annular flume, the selected H. molitrix were injected with a 1/10 dosage of luteinizing hormone-releasing hormone antagonist-2 (LHRH A2). They were tested for three days or until eggs were laid in each scenario. After each test, female H. molitrix were anesthetized using a sublethal dose of NaOH-neutralized MS-222 and dissected to confirm the number of spawning females according to ovarian saturation.

To test the effects of flow velocity on embryo development, a small annular flume was set up (Fig. S3b in Supporting Information), which used small booster pumps to control the flow velocity. Three scenarios with designed maximum flow velocity of $0.4,0.8$, and $1.2 \mathrm{~m} / \mathrm{s}$ were tested. Each velocity treatment was repeated in triplicate. The total hatch ratio and the survival ratio of newly hatched larvae $24 \mathrm{~h}$ post-hatch were used to assess the embryo development. Water quality parameters were measured in the same way as above. In the small annular flumes, a constant water level was maintained and half of the water was replaced every day. Two hundred fertilized eggs were selected to assess the development of embryos in each test if spawning happed.

To obtain the flow velocity of the entire annular flume, computational fluid dynamics (CFD) method was used in the study, which was implemented in CFX (ANSYS CFX 11.0). The model was calibrated and validated by the observed data from the twenty-two measuring points. The details of the model description, calibration and verification were presented in Text S3 in Supporting Information.

Statistical analysis of experimental data. The experimental data and the measured data as well as the computed flow velocity data were analyzed by one-way ANOVA to determine the effects of flow velocity on the spawning and embryo development of $H$. molitrix. Significance was analyzed using Duncan's multiple range test and Tukey's student range test at a significance of 0.05 . Data were expressed as mean \pm standard error (SE). All analyses were conducted using SigmaPlot 11.0 (Systat Software, the US/Canada).

\section{Results}


Reproduction of $\boldsymbol{H}$. molitrix in field surveys in mid-Yangtze River. From the five-year field surveys, 20 spawning events (dashed boxes) were detected, among which 11 peak spawning events (higher dashed boxes) were identified (Fig. 1).

[Please insert Fig.1 here]

During the sampling periods, water temperatures were at suitable levels, ranging from 18.5 to $24.0^{\circ} \mathrm{C}$ (Table S2 in Support Information). Egg identification showed that about $55 \%$ of collected eggs belonged to silver carp, and $38 \%$ belonged to grass carp, and $5 \%$ belonged to black carp, and only $1 \%$ belonged to bighead carp. The results also indicated that the egg proportions of different Chinese carp species were similar every year, which meant there was no significant change in the proportion between the five years. The development stage of fish embryos was clarified to determine the drift time of eggs. The identified eggs were predominantly at last blastula stage, which accounted for $72.42 \%$ of the total, while $27.68 \%$ of the examined eggs were identified as the other developmental stages (Table S3 in Support Information).

The calibration and validation results of hydrodynamic model were shown in Fig. S4 in Supporting Information. It was seen that the relative root mean square error for flow velocity and water level during validation ranged from $0.7^{\sim} 4.1 \%$ and $0.15^{\sim} 0.23 \%$, respectively, implying that the modeled flow fields of the river reach (Fig. S2 in Supporting Information) were reliable. The determined spawning sites showed that the locations of spawning events were between Yanzhiba and Honghuatao (Fig. S2 in Supporting Information), which were consistent with previous studies ( $\mathrm{Li}$ et al. 2016). The corresponding flow velocities of each spawning event at the located sites were extracted from the hydrodynamic model results and were analyzed with the egg densities (Fig. 1). The statistic results (Fig. 2) showed that in the surveyed river reach, the flow velocity triggering $H$. molitrix to spawn was $1.30 \pm 0.20 \mathrm{~m} / \mathrm{s}$ (Fig. 2a), and the preferential velocity for $H$. molitrix to spawn was $1.40 \pm 0.23 \mathrm{~m} / \mathrm{s}$ (Fig. 2b).

[Please insert Fig.2 here]

Reproduction of $\boldsymbol{H}$. molitrix in flume simulation experiments. The flow fields of the large annular flume for different experiment scenarios were shown in Fig. S5 in Supporting Information. Since no spawning activity was observed for the experimental scenarios with a maximum velocity of 0.8 and $1.8 \mathrm{~m} / \mathrm{s}$, the results were not taken for further analysis. The videos from the five underwater cameras (Fig. S3 in Supporting Information) showed that all the spawning activities (see Breeding fish.avi and Spawned eggs.avi) happened in bend sections. Accordingly, the flow velocities at these bends were extracted from the CFD simulated flow fields for further analyses. The ratio of spawned females to total tested females was plot with the extracted flow velocity for each experimental scenario (Fig. 3a). The ratio increased significantly with the increase in flow velocity until $1.4 \mathrm{~m} / \mathrm{s}$, and then decreased sharply at $1.6 \mathrm{~m} / \mathrm{s}$. The highest ratio of spawned female, which reached $67 \%$, was observed at the flow velocity of $1.4 \mathrm{~m} / \mathrm{s}$ (Fig. 3a). However, the maximum fertilization ratio of eggs occurred at the flow velocity of $1.2 \mathrm{~m} / \mathrm{s}$ (Fig. 3b), and it was significantly higher than those at the velocity of 1.0 and $1.6 \mathrm{~m} / \mathrm{s}$. There was no significant difference in fertilization ratio between 1.2 and 1.4 $\mathrm{m} / \mathrm{s}$.

[Please insert Fig.3 here]

The total hatch ratio of $H$. molitrix embryo declined with the increase in flow velocity (Fig. 3c). At the velocity of $1.2 \mathrm{~m} / \mathrm{s}$, the hatch ratio was as low as $15 \%$. The survival ratio of newly hatched larvae in 24 $\mathrm{h}$ showed a similar trend to the total hatch ratio. The survival ratio was about $12 \%$ in static water and decreased to $4 \%$ at $1.2 \mathrm{~m} / \mathrm{s}$.

Consistency between experimental and field results. In the flume experiments, the highest egg density appeared at the flow velocity of $1.4 \mathrm{~m} / \mathrm{s}$ and the lowest egg density was at the flow velocity of $1.6 \mathrm{~m} / \mathrm{s}$ (Fig. 4a). The analyses on the spawning event data from the field showed that a velocity range from 1.05 to 1.60 $\mathrm{m} / \mathrm{s}$ was suitable for $H$. molitrix to spawn in natural water bodies (Fig. $4 \mathrm{~b}$ ).

[Please insert Fig.4 here] 
The egg density data from both experiments and field surveys were normalized according to Vismara et al (Vismara et al. 2001). The normalized spawning data $(S)$ and the flow velocity $(v)$ were fitted using Gaussian regression, which gave $\mathrm{S}=e^{-\frac{(v-1.3062)^{2}}{0.0707}}\left(\mathrm{R}^{2}=0.929, p<0.0001\right)$ for the flume experiments (Fig. $5)$ and $S=e^{-\frac{(v-1.3143)^{2}}{0.0968}}\left(\mathrm{R}^{2}=0.983, p<0.0001\right)$ for the field surveys. The results from experiment and from observations were highly consistent, which could be written as $S=e^{-\frac{(v-1.31)^{2}}{0.097}}$. Therefore, a compromised optimal flow velocity of $1.31 \mathrm{~m} / \mathrm{s}$ was identified, considering the requirements of spawning and hatching and larvae development, for reproduction of $H$. molitrix in rivers.

[Please insert Fig.5 here]

\section{Discussion}

We quantified the effects of flow velocity on the spawning and embryo development of $H$. molitrix , a species spawning drifting eggs, through field measurements and lab experiments. Our research offered direct evidence that a certain flow velocity was a prerequisite for silver carp to spawn. In the flume experiments, the percentage of successfully spawned female silver carp increased with the increase in flow velocity, and reached the maximum at a flow velocity of $1.4 \mathrm{~m} / \mathrm{s}$ (Fig. 3). However, when flow velocity was as high as 1.6 $\mathrm{m} / \mathrm{s}$, the spawning activity was severely inhibited, which was due to the excessive physical exertion for $H$. molitrix to keep swimming. In the natural spawning sites of Yangtze River, silver fish eggs were observed at a wider velocity range from 1.05 to $1.60 \mathrm{~m} / \mathrm{s}$ (Fig. 1). The wider range of preferential flow velocity in natural water bodies could be attributed to the complicated hydrological conditions and habitat characteristics. Besides preferential flow velocity for $H$. molitrix spawning, triggering velocity was another important factor. No spawning activity was observed in flume at a velocity of $0.8 \mathrm{~m} / \mathrm{s}$, and the determined triggering velocity was about $1.0 \mathrm{~m} / \mathrm{s}$ (Fig. 4). In the natural river reach, spawning was observed at a velocity range from 0.9 to $1.90 \mathrm{~m} / \mathrm{s}$ (Fig. 4). The required flow velocity for spawning differs largely among different fish species. Female Atlantic salmon constructs spawning redds in areas with an averaged flow velocity of $0.53 \mathrm{~m} / \mathrm{s}$ (Beland et al. 1982), while the spawning of medeka (Oryzias latipes) decreases under flowing water and recovers when water flow stops (Kitamura \& Kobayashi 2003). Our research demonstrated that though silver carp is widely found living and growing in relatively lentic habitats (Kocovsky et al.2012), a certain velocity of water flow is necessary for its reproduction.

Flow velocity was not only a trigger for the spawning activity of $H$. molitrix, but also influenced the fertilization ratio of eggs. The highest fertilization ratio was observed at $1.2 \mathrm{~m} / \mathrm{s}$, but there was no significant difference in fertilization ratios between 1.2 and $1.4 \mathrm{~m} / \mathrm{s}$ (Fig. 3). Due to the external fertilization character of silver carps, the sperm-egg fusion happens in water through mixing effects induced by water flow. Because the swimming ability of sperm was limited both temporally and spatially (Islam \& Akhter 2011), a flow velocity higher than $1.6 \mathrm{~m} / \mathrm{s}$ caused a rapid decrease in fertilization due to the failure of encounters between sperm and eggs. After fertilization, eggs need to be hatched under a certain flow velocity, as the eggs of silver carp are semi-buoyant and must remain suspended during the development of early life stage. Garcia et al. (Garcia et al. 2015) has studied the sedimentation of silver carp eggs at different flow velocities and found that $0.2 \mathrm{~m} / \mathrm{s}$ could support the suspension of eggs. However, in this study, both the hatch ratio and survival ratio of newly hatched larvae of silver carp decreased significantly with the increase in flow velocity. It seemed that lentic water was more favorable to the early life stage development. According to Murphy and Jackson (Murphy \& Jackson 2013), flow velocity as low as 0.15 to $0.25 \mathrm{~m} / \mathrm{s}$ could be sufficient to suspend the silver carp eggs in four tributaries of the Great Lakes. The early life stages of fish, especially during the rapidly growing embryo and larval stages, are most suitable for assessing environmental pressure, as the larvae and juvenile fish are more prone to environmental stress than adults (Amado \& Monserrat 2010). Small changes in environmental factors may cause considerable variation in phenotype, resulting in a significant impact on survival and development in later ontogeny (Johnston et al. 2001). Excessive flow velocity causes mechanical damage to eggs (Garciaet al. 2015), which could be the main reason for the inhibition of both egg hatching and larval survival. After fertilization, eggs floated downstream, and embryonic development happened in relatively slow currents. Otherwise, even though the higher flow velocity could stimulate spawning of fish, 
they did not lead to increased recruitment because larval survival was low under rapid flows (Haworth \& Bestgen 2016). Besides the major function of water flow to maintain the eggs in suspension, water exchange and dissolved oxygen content is also increased at higher flow velocity, which can benefit to hatching. In our flume experiment, the water depth was not as large as in natural water bodies and the egg densities were low as well, therefore the oxygen conditions were not the limiting factor for the development of early life stage. In natural water bodies, the preferential flow velocity for egg hatching of $H$. molitrix needs to be further determined.

It has been well known that the breeding performance of teleosts is regulated by pituitary hormones, especially gonadotropin $(\mathrm{GtH})$, which are regulated by gonadotropin releasing hormone (GnRH) (Peter 1983). Environmental conditions, such as a rising discharge, long photoperiod and warm temperatures, are thought to be important factors controlling the reproduction cycles in teleosts. The activity of GnRH is observed to be up-regulated under the environmental factors that stimulate gonadal activity (Rodriguez et al. 2004). A rising discharge has been reported to be the primary cue for spawning of many teleosts, including silver carp. Unlike common carps, for example Cyprinus carpio, silver carp are unable to spawn naturally in lentic water, because of the stagnation of ovary development in mature females of silver carps. The artificial injection of LHRH A2 has been demonstrated to be effective to induce spawning of silver carp (El-Hawarry et al. 2012). In our experiment, LHRH A2 was applied to investigate the necessity of flow velocity in the induction of spawning of silver carp. A flow velocity of $0.8 \mathrm{~m} / \mathrm{s}$ could not trigger the spawning activity of silver carp even after the injection of LHRH A2, and spawning occurred only when the flow velocity reached $1.0 \mathrm{~m} / \mathrm{s}$.

In China, the Yangtze River is the main habitat for silver carp. There are several dams in the upper and middle reach of the river, which is known to have caused the loss of spawning grounds for Chinese carps (Yiet al. 2010). The establishment of new spawning grounds will highly affect the maintenance of the population. This study offered the explicit range of flow velocity required for spawning of silver carp, which provided an essential clue to dam operation for Chinese carp conservation. In contrast to the population depression in Yangtze River, Chinese carps are causing serious ecological disasters in many countries as an invasive species. Silver carp has been introduced to at least 88 countries or territories for aquaculture or for controlling algal blooms or as invasive species, and more than a third of these introductions have already established selfsustaining populations (Kolar et al. 2007). The introductions have caused severe consequences due to the competitive advantage of silver carp over native species and profound influence on plankton communities in the long term (Irons et al.2007). It is reported that the biomass of silver carp comprised $51 \%$ of total fish collections in the La Grange Reach of the Illinois River in 2008 (Sass et al. 2010). High phenotypic plasticity in breeding traits is the reason for the successful establishment of the new populations (Coulter et al. 2013). Meanwhile, a series of physical and non-physical barriers, including dam blocking (Zielinskiet al. 2018), electric dispersal barriers (Parker et al.2015), acoustic stimuli barriers (Murchy et al. 2017), or biological methods, including employment of koi herpesvirus (Lighten \& van Oosterhout 2017) and the introduction of female-specific-sterility and female-specific-lethality individuals (Thresher et al. 2014), have been applied to suppress the spreading of silver carp populations. However, these measures have not successfully solved the problem, and even worse, some of them have induced unexpected ecological risks (Kopfet al. 2017; Marshall et al. 2018). Since spawning and early life stage development play the primary role in the establishment of an invasive species, blocking the spawning process will be of critical importance to the control of invasion. The flow velocity requirement is rigid in the spawning of silver carp, but is much more flexible during the rest of the life stages (Islam \& Akhter 2011). Therefore, manipulating flow velocity by dams can be a costeffective way to suppress the invasion of $\mathrm{H}$. molitrix . Given that most of big rivers in the world are heavily dammed, the findings provided a fundamental basis to manipulate flow velocities during reproduction season to enhance (1.2 [?] $v$ [?] $1.4 \mathrm{~m} / \mathrm{s})$ or control $(v<0.8 \mathrm{~m} / \mathrm{s}$ or $v>1.8 \mathrm{~m} / \mathrm{s})$ the population of carps by adapting operations of cascade dams.

\section{Acknowledgements}

This work is supported by the National Key Research and Development Program of China (No. 
2016YFC0502205), the National Natural Science Foundation of China (No. 51425902).

\section{Author Contributions}

Q.C. designed and supervised the study and revised the manuscript. L.T. and Y.G. collected the field spawning data. J.W. performed the laboratory experiments. L.T. and J.W. analyzed the data and drafted the manuscript. K. M. and Y.C. prepared figures and tables.

\section{References}

1. Amado, L.L. \& Monserrat, J.M. (2010). Oxidative stress generation by microcystins in aquatic animals: why and how. Environment International , 36, 226-235.

2. Beland, K.F., Jordan, R.M. \& Meister, A.L. (1982). Water depth and velocity preferences of spawning Atlantic salmon in Maine rivers.North American Journal of Fisheries Management , 2, 11-13.

3. Best, J. (2019). Anthropogenic stresses on the world's big rivers. Nature Geoscience, 12, 7-21.

4. Buddendorf, W., Malcolm, I., Geris, J., Fabris, L., Millidine, K., Wilkinson, M. et al. (2017). Spatiotemporal effects of river regulation on habitat quality for Atlantic salmon fry. Ecological Indicators , 83, 292-302.

5. Cao, L., Naylor, R., Henriksson, P., Leadbitter, D., Metian, M., Troell, M. et al. (2015). China's aquaculture and the world's wild fisheries. Science, 347, 133-135.

6. Cella-Ribeiro, A., da Costa Doria, C.R., Dutka-Gianelli, J., Alves, H. \& Torrente-Vilara, G. (2017). Temporal fish community responses to two cascade run-of-river dams in the Madeira River, Amazon basin.Ecohydrology, 10, e1889.

7. Chick, J.H., Gibson-Reinemer, D.K., Soeken-Gittinger, L. \& Casper, A.F. (2019). Invasive silver carp is empirically linked to declines of native sport fish in the Upper Mississippi River System.Biological Invasions , 1-12.

8. Cooper, A.R., Infante, D.M., Daniel, W.M., Wehrly, K.E., Wang, L. \& Brenden, T.O. (2017). Assessment of dam effects on streams and fish assemblages of the conterminous USA. Science of the Total Environment , 586, 879-889.

9. Coulter, A.A., Keller, D., Amberg, J.J., Bailey, E.J. \& Goforth, R.R. (2013). Phenotypic plasticity in the spawning traits of bigheaded carp (Hypophthalmichthys spp.) in novel ecosystems. Freshwater Biology, 58, 1029-1037.

10. Davies, P.M., Naiman, R.J., Warfe, D.M., Pettit, N.E., Arthington, A.H. \& Bunn, S.E. (2014). Flowecology relationships: closing the loop on effective environmental flows. Marine and Freshwater Research, 65, 133-141.

11. Ding, C., Jiang, X., Xie, Z. \& Brosse, S. (2017). Seventy-five years of biodiversity decline of fish assemblages in Chinese isolated plateau lakes: widespread introductions and extirpations of narrow endemics lead to regional loss of dissimilarity. Diversity and Distributions , 23, 171-184.

12. Duan, X., Liu, S., Huang, M., Qiu, S., Li, Z., Wang, K. et al. (2009). Changes in abundance of larvae of the four domestic Chinese carps in the middle reach of the Yangtze River, China, before and after closing of the Three Gorges Dam. In: Chinese Fishes . Springer, pp. 13-22.

13. El-Hawarry, W., Nemaatallah, B. \& Shinaway, A. (2012). Induced spawning of silver carp, Hypophthalmichthys molitrix using hormones/hormonal analogue with dopamine antagonists. Online Journal of Animal and Feed Research , 2, 58-63.

14. Fellman, J.B., Hood, E., Nagorski, S., Hudson, J. \& Pyare, S. (2019). Interactive physical and biotic factors control dissolved oxygen in salmon spawning streams in coastal Alaska. Aquatic Sciences , 81, 2. 
15. Finch, C., Pine III, W. \& Limburg, K. (2015). Do hydropeaking flows alter juvenile fish growth rates? A test with juvenile humpback chub in the Colorado River. River Research and Applications , 31, 156-164.

16. Garcia, T., Murphy, E.A., Jackson, P.R. \& Garcia, M.H. (2015). Application of the FluEgg model to predict transport of Asian carp eggs in the Saint Joseph River (Great Lakes tributary). Journal of Great Lakes Research , 41, 374-386.

17. Glotzbecker, G.J., Ward, J.L., Walters, D.M. \& Blum, M.J. (2015). Turbidity alters pre-mating social interactions between native and invasive stream fishes. Freshwater Biology , 60, 1784-1793.

18. Haworth, M.R. \& Bestgen, K.R. (2016). Flow and water temperature affect reproduction and recruitment of a Great Plains cyprinid.Canadian Journal of Fisheries and Aquatic Sciences , 74, 853-863.

19. Irons, K.S., Sass, G., McClelland, M. \& Stafford, J. (2007). Reduced condition factor of two native fish species coincident with invasion of non-native Asian carps in the Illinois River, USA Is this evidence for competition and reduced fitness? Journal of Fish Biology , 71, 258-273.

20. Islam, M.S. \& Akhter, T. (2011). Tale of fish sperm and factors affecting sperm motility: a review. Advances in Life Sciences, 1, 11-19.

21. Johnston, I., Vieira, V. \& Temple, G. (2001). Functional consequences and population differences in the developmental plasticity of muscle to temperature in Atlantic herring Clupea harengus.Marine Ecology Progress Series , 213, 285-300.

22. King, A.J., Gwinn, D.C., Tonkin, Z., Mahoney, J., Raymond, S. \& Beesley, L. (2016). Using abiotic drivers of fish spawning to inform environmental flow management. Journal of Applied Ecology , 53, 34-43.

23. Kitamura, W. \& Kobayashi, M. (2003). The effect of water flow on spawning in the medaka, Oryzias latipes. Fish Physiology and Biochemistry , 28, 429-430.

24. Kocovsky, P.M., Chapman, D.C. \& McKenna, J.E. (2012). Thermal and hydrologic suitability of Lake Erie and its major tributaries for spawning of Asian carps. Journal of Great Lakes Research, 38, 159-166.

25. Koehn, J. (2016). A powerful invader: Carp in Australia. Wildlife Australia, 53, 43.

26. Kolar, C.S., Chapman, D.C., Courtenay Jr, W.R., Housel, C.M., Williams, J.D. \& Jennings, D.P. (2007). Bigheaded carps: a biological synopsis and environmental risk assessment. American Fisheries Society, USA.

27. Kopf, R.K., Nimmo, D.G., Humphries, P., Baumgartner, L.J., Bode, M., Bond, N.R. et al. (2017). Confronting the risks of large-scale invasive species control. Nature Ecology $\&$ Evolution , 1, 1-4.

28. Lechner, A., Keckeis, H., Schludermann, E., Humphries, P., McCasker, N. \& Tritthart, M. (2014). Hydraulic forces impact larval fish drift in the free flowing section of a large European river. Ecohydrology , 7, 648-658.

29. Li, J., Xia, Z. \& Wang, Y. (2013). A time-series model for assessing instantaneous physical conditions in carp habitats.Ecohydrology , 6, 393-401.

30. Li, M., Duan, Z., Gao, X., Cao, W. \& Liu, H. (2016). Impact of the Three Gorges Dam on reproduction of four major Chinese carps species in the middle reaches of the Changjiang River. Chinese Journal of Oceanology and Limnology, 34, 885-893.

31. Lighten, J. \& van Oosterhout, C. (2017). Biocontrol of common carp in Australia poses risks to biosecurity. Nature Ecology \& Evolution, 1, 0087.

32. Marshall, J., Davison, A.J., Kopf, R.K., Boutier, M., Stevenson, P. \& Vanderplasschen, A. (2018). Biocontrol of invasive carp: risks abound. Science, 359, 877.

33. McBride, R.S., Somarakis, S., Fitzhugh, G.R., Albert, A., Yaragina, N.A., Wuenschel, M.J. et al. (2015). Energy acquisition and allocation to egg production in relation to fish reproductive strategies. Fish 
and Fisheries , 16, 23-57.

34. Murchy, K., Cupp, A.R., Amberg, J.J., Vetter, B.J., Fredricks, K.T., Gaikowski, M.P. et al. (2017). Potential implications of acoustic stimuli as a non-physical barrier to silver carp and bighead carp.Fisheries Management and Ecology , 24, 208-216.

35. Murphy, E.A. \& Jackson, P.R. (2013). Hydraulic and water-quality data collection for the investigation of Great Lakes tributaries for Asian carp spawning and egg-transport suitability. US Department of the Interior, US Geological Survey.

36. Normando, F.T., Santiago, K.B., Gomes, M.V.T., Rizzo, E. \& Bazzoli, N. (2014). Impact of the Três Marias dam on the reproduction of the forage fish Astyanax bimaculatus and A. fasciatus from the São Francisco River, downstream from the dam, southeastern Brazil. Environmental Biology of Fishes , 97, 309-319.

37. Parker, A.D., Glover, D.C., Finney, S.T., Rogers, P.B., Stewart, J.G. \& Simmonds Jr, R.L. (2015). Direct observations of fish incapacitation rates at a large electrical fish barrier in the Chicago Sanitary and Ship Canal. Journal of Great Lakes Research , 41, 396-404.

38. Peter, R.E. (1983). Chapter 3. The Brain and Neurohormones in Teleost Reproduction. In: Fish physiology (eds. Hoar, W, Randall, D \& Donaldson, E). Elsevier, pp. 97-135.

39. Poff, N.L. \& Schmidt, J.C. (2016). How dams can go with the flow.Science , 353, 1099-1100.

40. Rodriguez, L., Carrillo, M., Sorbera, L.A., Zohar, Y. \& Zanuy, S. (2004). Effects of photoperiod on pituitary levels of three forms of GnRH and reproductive hormones in the male European sea bass (Dicentrarchus labrax, L.) during testicular differentiation and first testicular recrudescence. General and comparative endocrinology , 136, 37-48.

41. Sass, G.G., Cook, T.R., Irons, K.S., McClelland, M.A., Michaels, N.N., O’Hara, T.M. et al. (2010). A mark-recapture population estimate for invasive silver carp (Hypophthalmichthys molitrix) in the La Grange Reach, Illinois River. Biological Invasions , 12, 433-436.

42. Solomon, L.E., Pendleton, R.M., Chick, J.H. \& Casper, A.F. (2016). Long-term changes in fish community structure in relation to the establishment of Asian carps in a large floodplain river.Biological Invasions , 18, 2883-2895.

43. Stone, R. (2016). Dam-building threatens Mekong fisheries.Science , 354, 1084-1085.

44. Thresher, R., Van De Kamp, J., Campbell, G., Grewe, P., Canning, M., Barney, M. et al. (2014). Sex-ratio-biasing constructs for the control of invasive lower vertebrates. Nature Biotechnology , $32,424$.

45. Vismara, R., Azzellino, A., Bosi, R., Crosa, G. \& Gentili, G. (2001). Habitat suitability curves for brown trout (Salmo trutta fario L.) in the River Adda, Northern Italy: comparing univariate and multivariate approaches. Regulated Rivers: Research \& Management , 17, 37-50.

46. Xie, P. \& Chen, Y. (2001). Invasive carp in China's plateau lakes.Science , 294, 999-1000.

47. Xu, W., Qiao, Y., Chen, X.J., Cai, Y.P., Yang, Z. \& Liu, H.G. (2015). Spawning activity of the four major Chinese carps in the middle mainstream of the Yangtze River, during the Three Gorges Reservoir operation period, China. Journal of Applied Ichthyology , 31, 846-854.

48. Yi, Y., Yang, Z. \& Zhang, S. (2010). Ecological influence of dam construction and river-lake connectivity on migration fish habitat in the Yangtze River basin, China. Procedia Environmental Sciences , 2, $1942-1954$.

49. Zhang, C., Ding, C., Ding, L., Chen, L., Hu, J., Tao, J. et al. (2019). Large-scale cascaded dam constructions drive taxonomic and phylogenetic differentiation of fish fauna in the Lancang River, China. Reviews in Fish Biology and Fisheries , 29, 895-916. 
50. Zielinski, D., Voller, V.R. \& Sorensen, P.W. (2018). A physiologically inspired agent-based approach to model upstream passage of invasive fish at a lock-and-dam. Ecological Modelling, 382, 18-32.

\section{Figure Legends}

Fig. 1 Fish spawning events and the corresponding flow velocity as well as velocity rising rate during 2012 to 2016 in mid-Yangtze River. The plotted data were collected from field surveys. The black curves show the flow velocity at the spawning site. The black hollow dots are the observed egg density. The red dash lines indicate spawning events. The blue triangles represent the egg density under triggering velocity, which is defined as the flow velocity when first spawning action took place in a spawning event. Red dots are the egg density under suitable velocity in which a prominent spawning occurred. The blue arrows indicate the velocity rising rate $(a)$ during spawning events.

Fig. 2 Histogram of spawning events at triggering velocity (a) and preferential velocity (b) in the Yangtze River.

Fig. 3 Reproduction of $\boldsymbol{H}$. molitrix at different flow velocities. The ratios of spawning females with flow velocity (a); fertilization ratios with flow velocity (b); the hatch ratio of fertilized eggs and survival ratio of larvae (c). The dots are the observed data, and the curves were fitted using one-dimensional Gaussian function.

Fig. 4 Fish reproduction against flow velocity. Normalized egg density at different velocity level and its Gaussian fitting curve in the flume experiments (a); the frequency histogram and the Gaussian fitting curve of spawning activities in natural spawning sites (b).

Fig. 5 The optimal flow velocity for reproduction of $H$. molitrix, considering both spawning and hatching requirements.
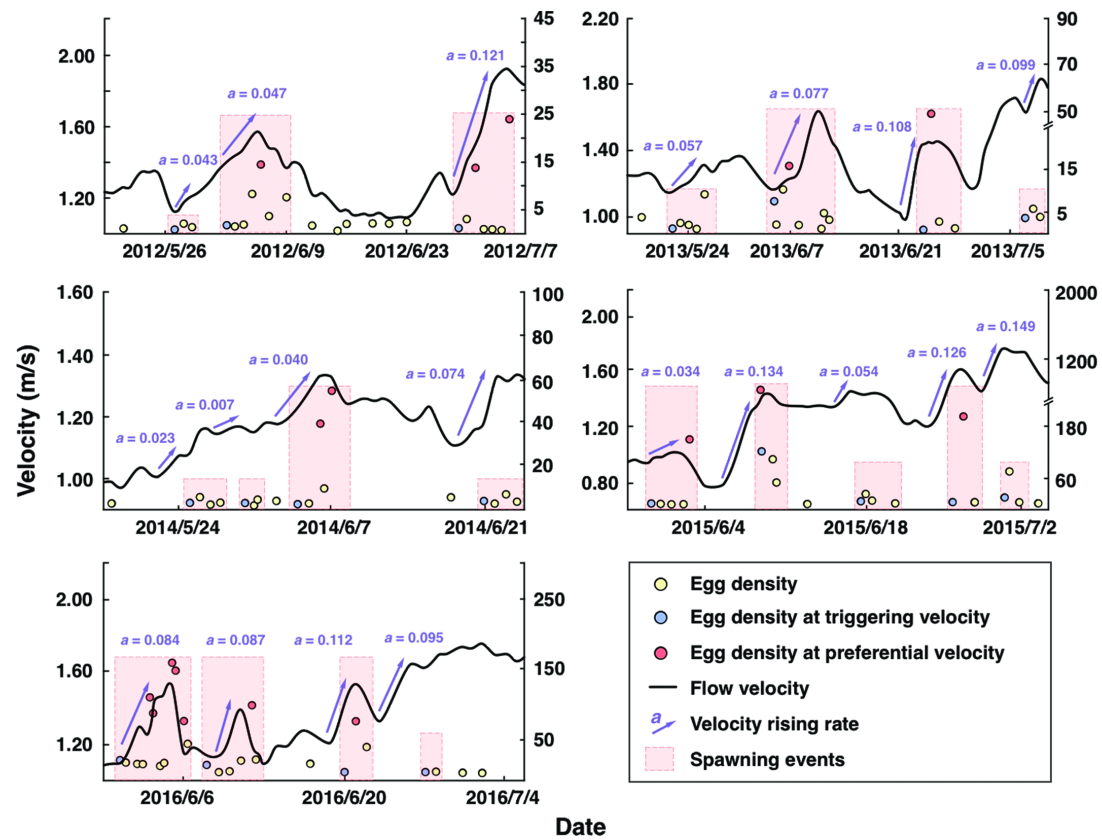

O Egg density

O Egg density at triggering velocity

- Egg density at preferential velocity

- Flow velocity

a. Velocity rising rate

Spawning events

Date 

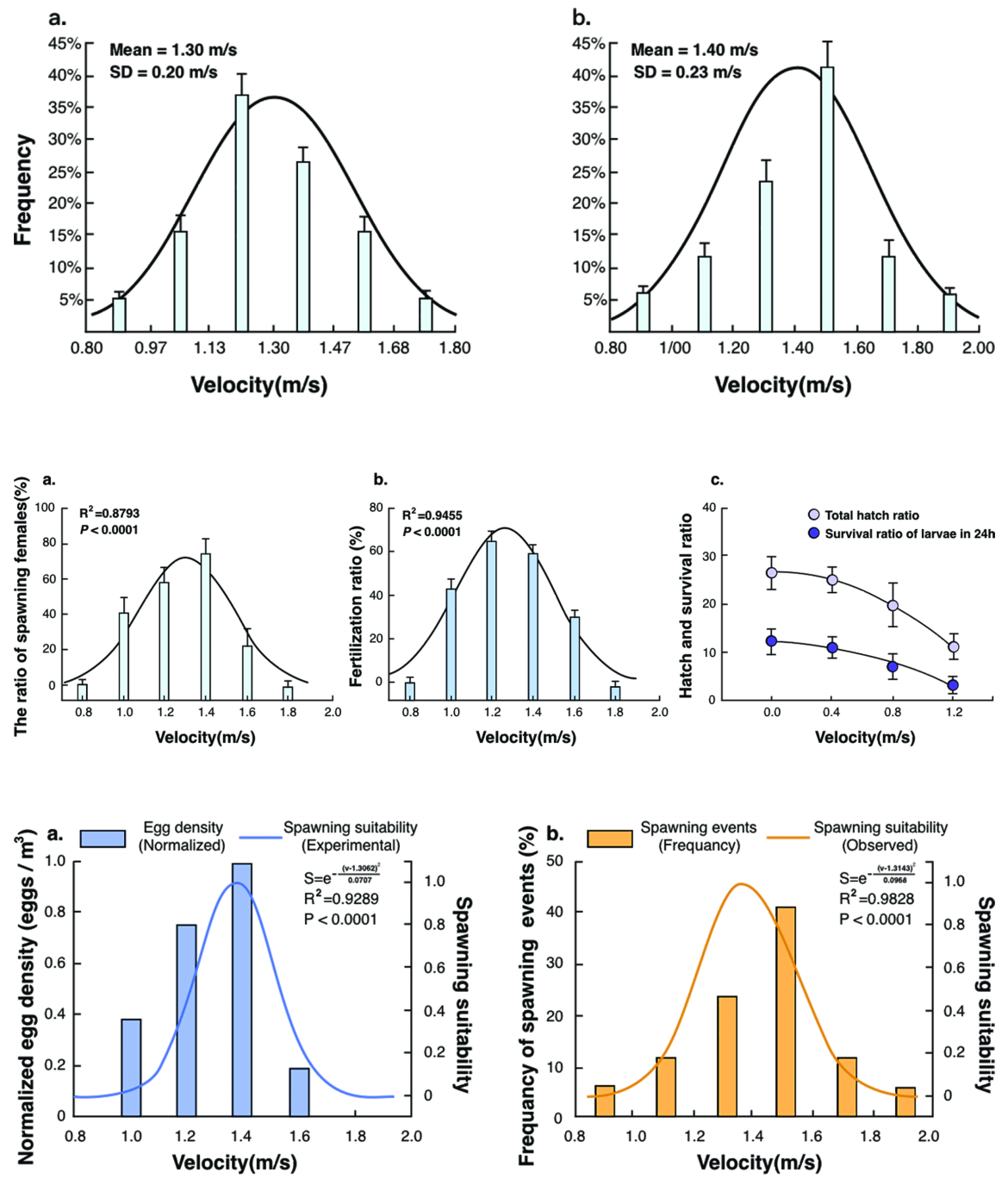


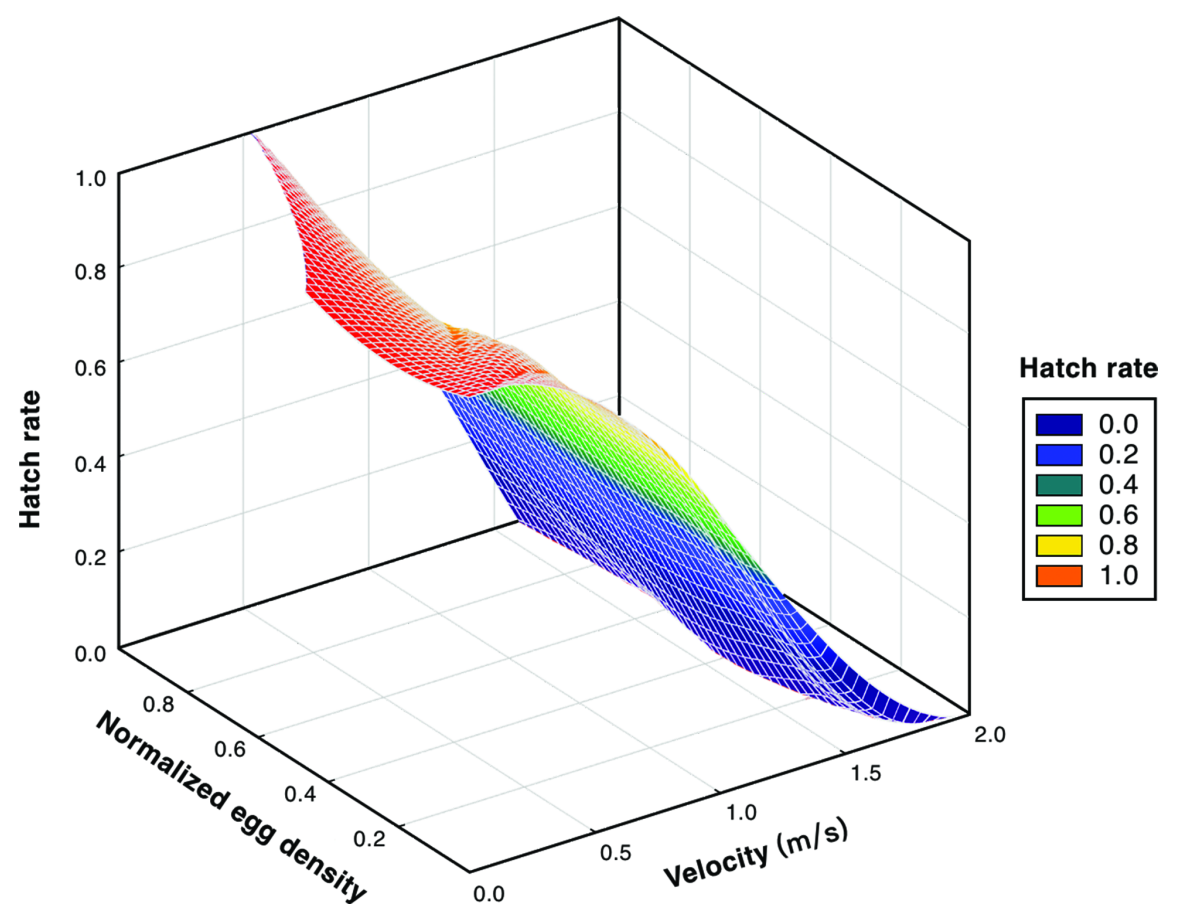

